\title{
Strategies for improving the lives of US women aged 40 and above living with HIV/ AIDS: an evidence map
}

\author{
Gaelen P. Adam ${ }^{1 *}$, Mengyang Di ${ }^{1}$, Susan Cu-Uvin ${ }^{1,2,3}$, Christopher Halladay', Bryant T. Smith', Suchitra lyer ${ }^{4}$
} and Thomas A. Trikalinos ${ }^{1,2}$

\begin{abstract}
Background: While in its early years the HIV epidemic affected primarily the male and the young, nowadays, the population living with HIV/AIDS is approximately $24 \%$ women, and its age composition has shifted towards older ages. Many of the older women who live with HIV/AIDS also live with the medical and social conditions that accompany aging. This work aims to identify and characterize empirical studies of strategies for the comprehensive management of women over 40, including transgender women, who live with HIV/AIDS. Forty was chosen as an operational age cutoff to identify premenopausal women who are less likely to bear children, as well as peri- and postmenopausal women.
\end{abstract}

Methods: We conducted a literature search after discussions with a diverse panel of content experts and other stakeholders and developed an evidence map that identified 890 citations that address questions having to do with programs and barriers to engaging with programs, as well as the role of insurance and comorbidities, and have enrolled older women who live with HIV/AIDS.

Results: Of these, only 37 (4\%) reported results of interest for women over 40 who live with HIV/AIDS, or examined interactions between gender and older age that would allow predictions in this subgroup. Few of the 37 eligible studies focused on women facing obvious challenges, such as immigrants, transgender, physically abused, or those recently released from prison. No studies focused on women caring for dependents, including children and grandchildren, or those diagnosed after age 40.

Conclusion: The evidence base that is directly applicable to women over 40 who live with HIV/AIDS in the USA is limited, and the research need is broad. We propose research prioritization strategies for this population.

\section{Background}

At the end of 2014, an estimated 955,081 people were living with human immunodeficiency virus (HIV) infection in the USA. While in its early years the epidemic affected primarily males and young people [1], nowadays, the population living with HIV/AIDS is approximately $24 \%$ women and its age composition has shifted [2]. The percentage of people living with HIV/AIDS aged 50 years and older grew from $24 \%$ in 2005 to $45 \%$ in 2014. This number is projected to top 50\% by 2020 [2, 3], but may have already done so [4]. People aged 40 and over comprise $72.5 \%$ of the population [2].

\footnotetext{
* Correspondence: Gaelen_adam@brown.edu

${ }^{1}$ Brown Evidence-based Practice Center, Brown University School of Public

Health, Box G-S121-8, Providence, RI 02912, USA

Full list of author information is available at the end of the article
}

Thus, the management of this population who live with HIV/AIDS represents a relatively new challenge.

It is well understood that the population of older people who live with HIV (for this report, all people over the age of 40 ) is heterogeneous with respect to a multitude of factors that are associated with length and quality of life [2].

Age at HIV infection, rather than age at diagnosis, may be important, because the natural history and prognosis of HIV and acquired immunodeficiency syndrome (AIDS) among those with HIV surviving into older age and those who were diagnosed at an older age appear to be distinct [5]. Further, compared to people who were infected young, people contracting HIV at an older age are not diagnosed as promptly and tend to start treatment at a more advanced stage of the disease. Of the 
428,724 people aged 50 and above living with AIDS at the end 2014, only $1.6 \%$ were diagnosed at age 50 and above; for those age 40 and above, the percentage was 1.9 .

Aging with HIV infection presents special challenges for preventing and managing comorbid conditions. Older women with HIV/AIDS may have an increased risk for cardiovascular disease, osteoporosis, and certain cancers than their uninfected counterparts [6-9]. According to a 2013 study by the CDC, the most common conditions among women infected with HIV were viral hepatitis B or $C$ coinfection $(29.0 \%)$ or were related to cardiovascular disease or metabolic syndrome, including dyslipidemia (67.3\%), hypertension (57.4\%), obesity (31.7\%), and low high-density lipoprotein cholesterol (27.3\%). They also noted that $73.7 \%$ of women across races and ethnicities had more than one comorbidity [10]. HIV-positive antiretroviral-treated older women who achieve viral suppression are in a generalized status of immune activation and therefore may be at an increased risk of ageassociated end-organ diseases compared to uninfected age-matched controls [11]. Polypharmacy is another common concern $[12,13]$.

Women over 40 living with HIV/AIDS also face issues related to the interaction between reproductive hormones, HIV/AIDS, and antiretroviral treatments. Some women may still have childbearing potential and will have unique contraceptive or fertility needs $[14,15]$, and there have been inconsistent reports regarding HIV and menopause [16-19].

Older women with HIV face challenges related to mood and psychosocial wellbeing. Compared to older women without HIV, older women with HIV infection are more likely to be depressed and lonely [20,21], and many are burdened with taking care of elderly parents or grandchildren [22]. Stigmatization can also contribute to depression and worry and may prevent women from disclosing their HIV status or from seeking care [23].

African American/Black women are disproportionally affected by HIV, compared to women of other race/ethnicities. An estimated $61 \%$ of women who were living with HIV/ AIDS in 2014 were African American [2]. Race is often a marker of socioeconomic and demographic factors related to health inequities, which may have a bearing on the comprehensive management of women living with HIV/AIDS. HIV rates are also highest among women living in areas where more than $21 \%$ of residents were below the federal poverty level [2].

Special consideration should be given to women who identify as lesbian, bisexual, or transgender (assigned male sex at birth but identify as women). For women who identify as lesbian, HIV infection may be diagnosed belatedly, and transgender women are a vulnerable subgroup for a number of medical and social reasons [24-29].
Ideally, the care of older women living with HIV/AIDS should support patient-centered approaches to managing HIV and comorbidities; incorporate patient goals, including quality of life issues; and integrate biomedical, behavioral, and social interventions [13, 30, 31]. Because people with HIV/AIDS may have an accelerated aging process and often suffer from multiple comorbidities, a geriatrics approach may be appropriate, even for those who are not chronologically geriatric [30,31].

However, the current system of care in the USA does not support a comprehensive model that can provide a tailored approach for older women living with HIV/ AIDS. This paper comprises an evidence map of the published literature on questions pertinent to older women, aged 40 and above, who live with HIV/AIDS to serve as a compendium of the evidence base (enabling further systematic study of specific questions) that can be used to identify and prioritize gaps in the evidence, without recording what the findings were or assessing risk of bias and the strength of the evidence (which was infeasible given the scope and heterogeneity of interventions and outcomes).

\section{Methods}

The protocol for this project was not registered with PROSPERO, but was posted prospectively on the Agency for Healthcare Research and Quality (AHRQ) Web site (https://effectivehealthcare.ahrq.gov/topics/women-hiv/ research-protocol/).

\section{Key informants}

We assembled a panel of eight Key Informants that included experts in the care of HIV patients, nationally recognized researchers, policy makers, state government (Department of Health) officials, and nationally recognized advocates for women who live with HIV/AIDS to share their perspective on the issues that the guiding questions address. Based on these discussions, we refined study eligibility criteria and data extraction items for the evidence map of empirical studies that apply to women over 40 who live with HIV/AIDS. We grouped the studies into three areas of interest: (Area 1) studies that measure the impact of or describe barriers to engaging with existing resources; (Area 2) studies that measure the impact of insurance coverage on outcomes related to engaging with a program or accessing care; and (Area 3) studies that assess the performance of diagnostics for co-occurring disease or assess the effects of treating co-occurring diseases or risk factors.

\section{Eligibility criteria}

Eligible studies reported results stratified by age and included at least $75 \%$ of the participants were women 40 years and older who live with HIV, an operational age 
cutoff to identify premenopausal women who are less likely to bear children, and peri- and postmenopausal women. All patient-level and system-level outcomes were eligible. Eligible services provided medical, behavioral, or social support or were programs that bundled several such services.

All study designs were eligible, including qualitative studies, which informed on barriers to accessing care. We excluded studies that analyzed fewer than 10 women who are older than 40 and live with HIV/AIDS, because they were unlikely to yield precise or broadly applicable conclusions. We also excluded studies completed longer than 10 years ago, because older empirical data are less likely to be relevant to today's setting. Because the main focus of the evidence map is to inform about the US setting, we did not include studies conducted exclusively in other countries. Finally, we excluded studies not reporting empirical data.

\section{Literature identification and data abstraction}

A medical librarian designed and implemented searches in PubMed, PsycINFO, CINAHL, and SocINDEX for terms related to HIV or AIDS, crossed with terms on interventions, policies, services, or programs. We limited the search to English language reports published after January 01, 2005, having at least one author with a US affiliation. The search was last run on February 10, 2016, and is reported in full in Additional file 1: Appendix 1 in the full report of the project [32]. After a pilot phase to ensure that the eligibility criteria was being correctly and uniformly applied, abstracts were single-screened by a human reviewer and double-checked against the predictions of the machine learning algorithms implemented in Abstrackr [33]. All potentially eligible citations were retrieved and screened in full text for eligibility. For these papers, we recorded reasons for exclusion. For papers on studies that were excluded only because they did not report subgroup-specific information or pertinent interaction analyses, we recorded the area of interest the paper fell into.

All data were extracted in a predefined electronic form by a single investigator. The form recorded bibliographic information; demographic details for women over 40 where available, and for all women in the study where not; along with details about the programs, barriers, insurance impact, and comorbidities. Due to the nature of the project, we did not extract results, nor did we make strength of evidence assessments for individual studies or for the whole evidence base.

\section{Results}

We screened 9054 unique abstracts for eligibility, of which 1763 were selected for full text review. In the end, 32, 7, and 8 papers were eligible for the three areas of interest, respectively (Fig. 1). Of the citations that were excluded in full text review, 854 were excluded because they did not provide information on strata of women who live with HIV/AIDS and are at least 40 years old or did not analyze interactions between gender and older age. Details on these studies are available in Additional file 1: Appendix B.

\section{Area 1: studies measuring the impact of strategies for engaging resources or describing barriers to accessing resources}

Thirty-two papers were eligible in Area 1; 16 quantified the impact of strategies for engaging resources, and 18 were about barriers to accessing resources (one paper was about both). Additional file 1: Appendix B, Table S1 summarizes the characteristics of the women enrolled in these studies. Most studies were conducted in urban centers, though a few focused on rural populations or examined differences between rural and urban populations. Studies included an average of 70 women (nine included more than 200 women). Mean ages ranged between 36 and 57 years, and no study provided results in the elderly. No study reported the women's menopausal status or the age at which they were diagnosed with HIV.

Among the 28 studies that reported information on the race/ethnicity of participants, the median proportion of African American, Latino/Hispanic, and White women was 78,15 , and $14 \%$, respectively. Three studies enrolled a small proportion of Native American women,

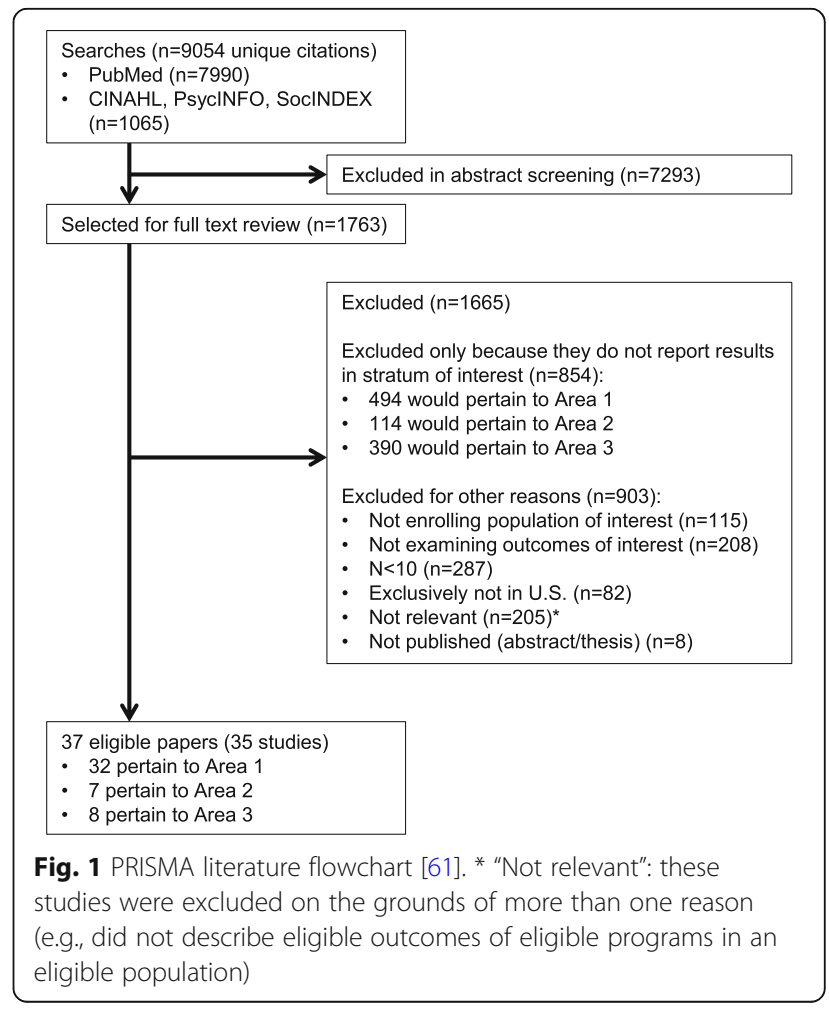


and one included Pacific Islander women. No study enrolled Asian women.

On average, $20 \%$ of women reported having a spouse or partner, $58 \%$ perceived having adequate social support, and $31 \%$ cared for a dependent, but such information was provided in less than a third of the studies. Among studies listing such information, the average proportion of women who had annual income less than approximately $\$ 10,000$ were unemployed, had not finished high school, used illegal substances, or faced mental health challenges ranged between 31 and $75 \%$. Only one or two studies reported on the proportion of women who were undocumented immigrants (one study), experienced violence (two studies), or had a history of incarceration (one study).

Cumulative data from seven studies reported that a median of $73 \%$ of women had some form of public insurance (Medicare or Medicaid), $15 \%$ had private insurance, and $27 \%$ had no insurance. However, this may have changed or be changing as the Affordable Care Act is implemented.

Finally, the vast majority of studies did not explicitly report information on sex of women's sexual partners or gender self-identification. No study reported the proportion of women who have more than one concurrent sexual partner, four studies included women who were identified in the study as lesbian or bisexual (ranging from 6.6 to $33 \%$ of the study population), and one study enrolled only transgender women.

\section{Studies measuring the impact of strategies for engaging resources}

Sixteen papers on 13 unique studies measured the impact of engaging with various services or with programs bundling several services. Eight RCTs (described in 10 papers) randomized between 30 and 184 participants to receive a specific program or an alternative (no program or a different program). An additional six studies qualitatively assessed the impact of engaging with programs. Three were based on interviews of 15 to 21 participants [34-36], a fourth examined a cohort of 364 participants in a stress-management intervention [37], and two examined programs aimed at reducing substance use in 46 and 76 participants, respectively [38, 39]. Details of all programs and measured outcomes are listed in Table 1.

\section{Studies of barriers to accessing resources}

Eighteen observational studies evaluated barriers to care in populations ranging from 17 to 1701 women. Almost all of the barriers studied involved engaging or retention in HIV care, though three studies exclusively assessed outcomes not related to HIV, including cancer screening (one study), accessing program services online (one study), and using the internet (one study) (Table 2). Of the 14 studies that evaluated barriers to accessing care or retention in care, the barriers were sociodemographic in 12 , cultural in 6 , psychosocial in 11 , having to do with experience with incarceration in 1 , having to do with medical history in 12, and having to do with mental history in 6. Two studies reported on barriers to cancer screening that were sociodemographic, psychosocial, and medical in nature $[40,41]$, and a third evaluated barriers to adherence to treatment in the context of a pharmacy program that were psychosocial and medical [35]. Two studies, both by Blackstock et al., evaluated barriers having to do with using the Internet, either in general or to access social support. These studies identified barriers from nearly every aspect (sociodemographic, cultural, psychosocial, medical history, and mental history) [42, 43], which may inform the design of Web-based programs, as well as strategies to enhance their uptake and use.

The most commonly cited system- or provider-level factors were lack of transportation and logistical challenges, including navigating, wait times, clinic hours, insurancerelated bureaucracy (six studies), and relationship with the provider (four studies).

\section{Area 2: studies measuring the effect of insurance}

Seven eligible papers evaluated the overall effect of insurance coverage levels on outcomes related to engaging with a program or accessing care. Six of these are included among the studies of barriers described in the previous section. Full details for the population are in Additional file 1: Appendix B, Table S2. Of these, six studies reported the impact of different insurance coverage on engagement with or retention in care, satisfaction with care, antiretroviral adherence, and Internet use. The seventh study evaluated the association between insurance coverage and successful management of major depressive disorder [44].

In no study did more than $18 \%$ of the women have private insurance. Where it was reported, between 60 and $100 \%$ of women had public insurance and between 7 and 35\% had no insurance. In all studies, insurance coverage was one of several factors in a regression model for engaging with or accessing care. Although we did not perform risk of bias assessments, we deem it unlikely that such analyses can yield good estimates of the causal effect of insurance on outcomes. These studies were not designed to estimate the causal effect of insurance, and each study considered and controlled for different variables.

\section{Area 3: studies on the diagnosis or management of comorbidity, or on predictive models}

Eight papers (seven studies), with sample sizes between 46 and 1234 participants, were deemed eligible. Full details for the population are in Additional file 1: Appendix B, Table S3. No study informed on diagnosis or screening for 


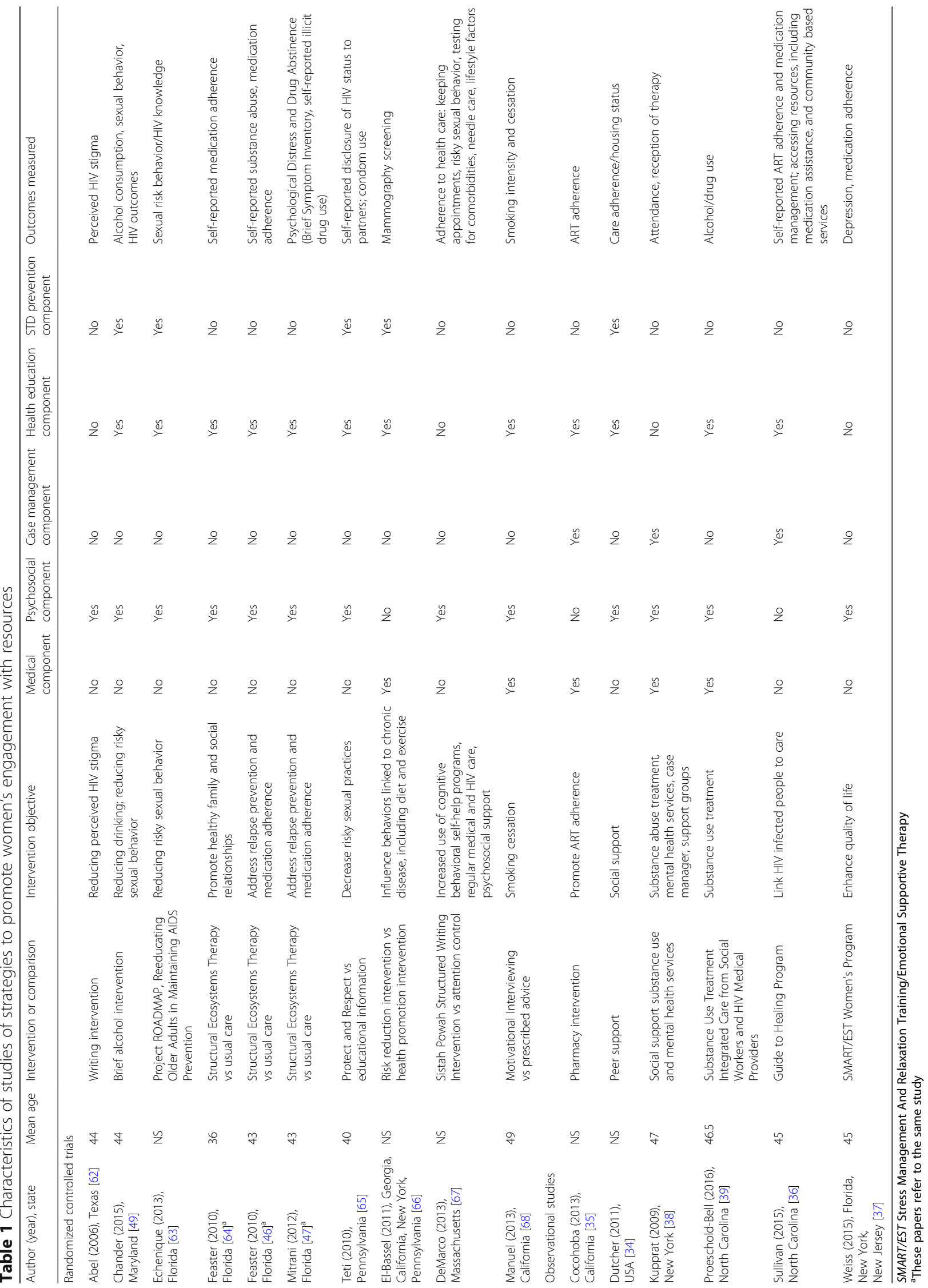




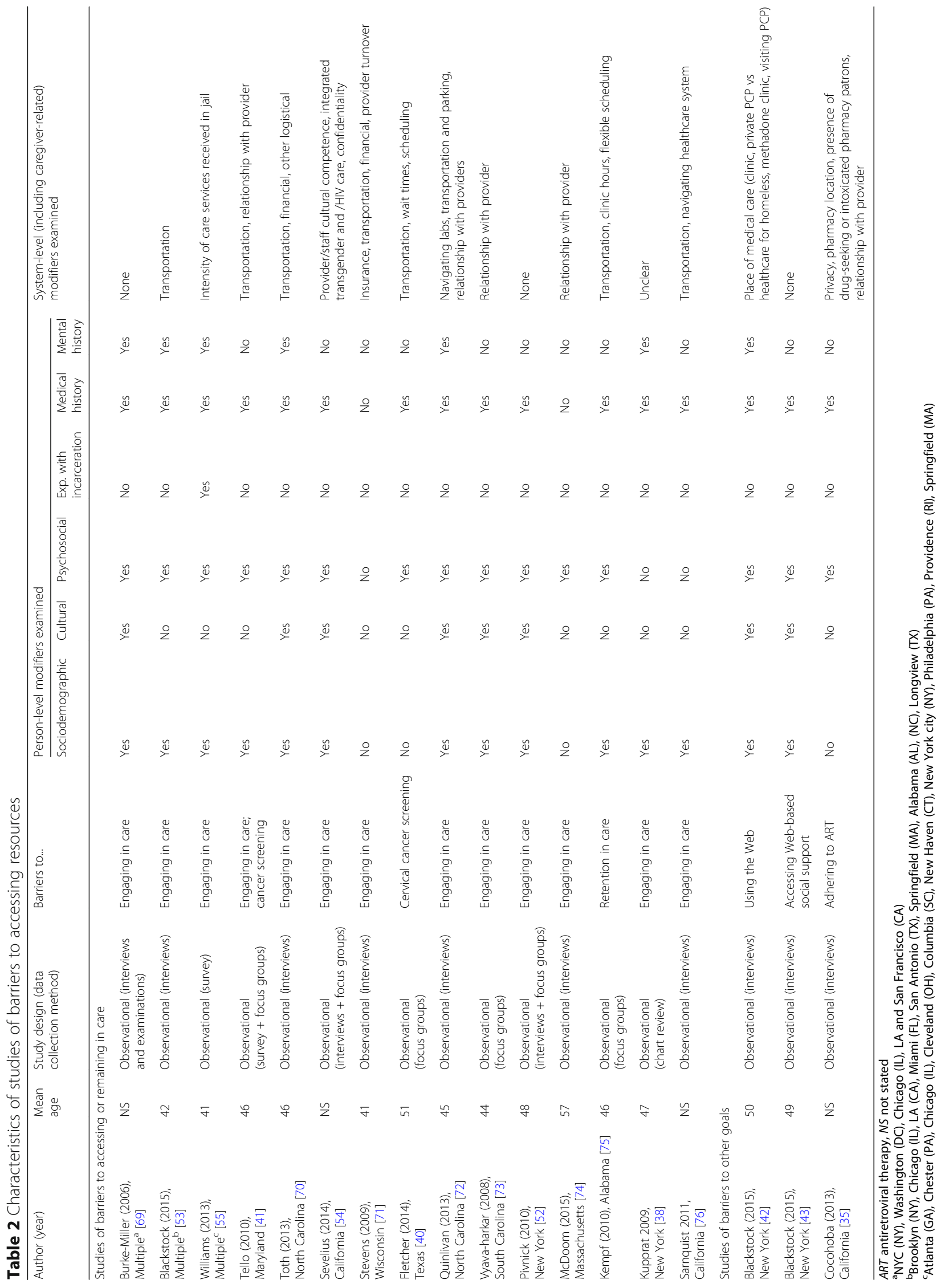


comorbidities among older women living with HIV/AIDS; six reported information on the management of comorbidities; and two reported on predictive models of HIV progression or overall mortality in the presence of comorbid conditions.

Of the six studies that included information on management of comorbidities, two pertained to depression, three to alcohol and other substance abuse, and one to cardiovascular disease. Of the two studies on depression, one examined whether psychopharmacologic and psychotherapeutic treatment of depressed HIV-women met standards defined in the best practice literature and assessed predictors of standard-concordant care [44], and the other examined whether antidepressant use by HIV-positive patients results in better employment rates [45]. Among the three studies of drug and alcohol abuse, one evaluated a family-based intervention (Structural Ecosystems Therapy) compared to a psychoeducational intervention [46, 47]. A second looked at associations between heavy alcohol consumption and antiretroviral treatment initiation and mortality [48], and a third evaluated a brief intervention to reduce or eliminate alcohol consumption in seropositive women with heavy drinking problems [49]. Finally, a cohort study reported rates of acute myocardial infarction among HIV-positive patients with cardiovascular risk factors [50].

Two eligible cohort studies described models predicting HIV progression or overall mortality among older women living with HIV/AIDS who also have comorbidities. The first predicted clinical progression of HIV disease based on illicit drug use and various sociodemographic factors (such as age, race, and sexual history) and medical history factors (such as antiretroviral use, CD4 cell counts, and CDC category of HIV disease at baseline) [51]. The second predicted all-cause mortality among older women living with HIV/AIDS who also have substance and alcohol abuse problems based on sociodemographic factors (age and race), medical history factors (including using various drugs, alcohol and tobacco, having hepatitis $\mathrm{C}$, prior antiretroviral therapy, CD4 counts, and viral load), and mental health factors (including a history of depression, anxiety, or psychosis) [48].

\section{Discussion}

We identified 890 citations that address questions in the three areas of interest and have enrolled women age 40 and over, who live with HIV/AIDS. Of these, only 37 (4\%) studies reported results of interest among older women who live with HIV/AIDS or examined interactions between gender and older age that would allow extrapolation to this subgroup. An additional 494, 114, and 390 papers would have been eligible for the three areas of interest, had they reported the required information on women age 40 and over. This observation is not surprising, because the page restrictions on journal articles limit the examination of the many subgroups of interest. It is, however, congruent with the prediction of the Key Informants that evidence for age grouping would be sparse.

While some of the 37 eligible studies focused on populations facing obvious challenges, such as immigrant women [52], women who had suffered physical abuse [53], transgender women [54], and women recently released from prison [55], more studies are needed in these subgroups. No study focused on women caring for dependents, those diagnosed in old age, or those who face less obvious challenges. For example, no published data have assessed the safety and efficacy of hormone therapy on symptoms of menopause, cardiovascular risk, and bone disease among women living with HIV/AIDS [56]. The pharmacological interactions between hormone therapy and antiretroviral treatments are not well understood, with some studies reporting menopause at an earlier age among women living with HIV/AIDS compared to uninfected women [16-18, 56-59], and other studies suggesting that women with HIV have more vasomotor symptoms (e.g., hot flashes, night sweats) and mood issues during menopause [56].

We identified eight generally small randomized trials that examined the impact of strategies for promoting healthy family and social relationships and healthier lifestyle. Most included psychosocial and health education components, but none included a comprehensive casemanagement-based approach. A handful of nonrandomized studies also evaluated the effectiveness of strategies for promoting care. We identified 18 studies of barriers to accessing care, which most commonly examined barriers related to sociodemographic, psychosocial, and medical factors. A minority examined barriers related to cultural factors, experience with incarceration, or mental health. Several studies identified system-level barriers to engaging with care, including transportation, scheduling, insurance referrals, financial issues, and practical challenges, such as navigating a hospital building. Finally, very few studies examined the overall impact of insurance on outcomes, or the impact of comorbidity on the management of HIV infection or its progression. Thus, although we did not analyze the findings of the aforementioned studies in all clinical areas, it is highly unlikely that the identified body of evidence is close to maturity.

\section{Limitations}

This work has several limitations. We developed an evidence map to describe the amount and type of practically available evidence, but did not summarize findings of eligible studies. For feasibility, we did not consider research completed longer than 10 years ago, because older empirical data are less likely to be relevant to today's setting and for informing the future research agenda. We decided not to search EMBASE or any other 
large, international general database, because we deemed that the added benefit of searching multiple targeted databases was more cost and time efficient and would yield more relevant studies than a second large general database search [60].

We did not conduct a detailed analysis of the 37 eligible papers, prioritize outcomes by their importance, or do a detailed analysis of the risk of bias or the strength of evidence of individual studies or of the entire evidence base, because these tasks were not relevant to the goal of this project, which was to describe the literature in broad terms.

Because the main focus of the evidence map was to identify studies that inform about the US setting, we did not consider studies conducted exclusively in other countries. To operationalize this, we limited our search to papers in which at least one author had a US affiliation. In screening, we excluded a study only if it reported that it had been done exclusively outside the USA.

Because of limited time and resources, screening and data extraction were done by a single experienced reviewer. We believe that the overall picture of the research is accurate.

\section{Research needs}

The 37 eligible studies do not represent a mature evidence base. The evidence base is even more sparse if one considers that the identified studies focused on different research questions and cannot possibly cover the range of practically implementable interventions that should be examined. By their nature such interventions are complex, in that they have many versions, and their implementation and deployment can depend on the targeted population.

More generally, when the range of questions of interest is so large, and the directly applicable evidence base is so limited, most, if not all, questions can be characterized as under-researched. The following are some general observations, which may help those looking to prioritize this research:

1. There is a need for better quality demographic information for women over the age of 40 living with HIV/AIDS in the USA, to allow better understanding of their care needs.

2. A large amount of data have already been collected on women who are over 40 years and live with HIV in the context of studies that enrolled broader populations, but have not been analyzed for this subgroup. Substantial economy of resources can be had by encouraging re-analyses of existing datasets, with a focus on older women who live with HIV/AIDS.

3. It is also possible that inferences about women who live with HIV/AIDS in the USA and are older than 40 years can be generalized from studies that included broader populations. A plausible approach would be to analyze existing large studies to see whether and how inferences would change in subgroups defined by age or other factors. Other sources of this sort of data include claims data, the CDC Medical Monitoring Project, and large cohort studies, such as Women's interagency HIV study (WIHS), the NA Accord, the SUN study, and Ryan White data (HRSA).

4. Observing the great successes of clinical research consortia that were formed to address medical questions, such as the AIDS Clinical Trials Group network, and the Women's Interagency Health Study, we believe that encouraging analogous consortia for addressing questions related to health services research, barriers, social interventions, economics, and other aspects of living and aging with HIV might be fruitful.

\section{Conclusions}

The population of women over 40 living with HIV/AIDS is both growing and under-researched. More research is needed to learn about the challenges faced by these women and how they differ across demographics. It is important to identify the needs of women over 40 living with HIV/AIDS and engage them in the prioritization, design, and interpretation of research. This research should be aimed at facilitating a comprehensive model of care that can provide a tailored approach for older women living with HIV/AIDS across the continuum of care.

\section{Additional file}

Additional file 1: Appendix A. Complete search strategies and Appendix B. Characteristics of women in included studies. (DOCX 428 kb)

\section{Abbreviations}

AHRQ: Agency for Healthcare Research and Quality; AIDS: Acquired immunodeficiency syndrome; HIV: Human immunodeficiency virus

\section{Acknowledgements}

Not applicable

Funding

This project was funded under Contract No. 290-2015-00002-I from the Agency for Healthcare Research and Quality (AHRQ), U.S. Department of Health and Human Services (HHS). The authors of this manuscript are responsible for its content. Statements in the manuscript do not necessarily represent the official views of or imply endorsement by AHRQ or HHS.

Availability of data and materials

The full report with all related data is available at: https://www.ncbi.nlm.nih.gov/ pubmedhealth/PMH0091591/

\section{Authors' contributions}

GA, Sc-U, TT, and SI designed the study and wrote the protocol. GA designed the search. GA, MD, CH, and BS screened the citations and extracted the data. GA, Sc-U, and $\Pi$ analyzed the data and wrote the report. All authors read and approved the final manuscript. 


\section{Authors' information}

Not applicable

\section{Ethics approval and consent to participate}

Not applicable

\section{Consent for publication}

Not applicable

\section{Competing interests}

The authors declare that they have no competing interests.

\section{Publisher's Note}

Springer Nature remains neutral with regard to jurisdictional claims in published maps and institutional affiliations.

\section{Author details}

${ }^{1}$ Brown Evidence-based Practice Center, Brown University School of Public Health, Box G-S121-8, Providence, RI 02912, USA. ²Department of Health Services, Policy \& Practice, Brown University School of Public Health, Providence, USA. ${ }^{3}$ Department of Ob-Gyn and Medicine, Warren Alpert School of Medicine, Brown University, Providence, USA. ${ }^{4}$ Agency for Healthcare Research and Quality, U.S. Department of Health and Human Services, Rockville, MD, USA.

\section{Received: 13 October 2016 Accepted: 12 January 2018}

\section{Published online: 02 February 2018}

\section{References}

1. Berkelman RL, Heyward WL, Stehr-Green JK, Curran JW. Epidemiology of human immunodeficiency virus infection and acquired immunodeficiency syndrome. Am J Med. 1989;86:761-70

2. CDC. Diagnoses of HIV infection in the United States and dependent areas, 2015. HIV Surveillance Report. 2015;27:1-114

3. CDC. Diagnoses of HIV infection in the United States and dependent areas, 2008. HIV Surveillance Report. 2008;20:1-143

4. High KP, Brennan-Ing M, Clifford DB, Cohen MH, Currier J, Deeks SG, Deren S, Effros RB, Gebo K, Goronzy JJ, et al. HIV and aging: state of knowledge and areas of critical need for research. A report to the NIH Office of AIDS Research by the HIV and aging working group. J Acquir Immune Defic Syndr. 2012;60(Suppl 1):S1-18.

5. Guaraldi G, Zona S, Brothers TD, Carli F, Stentarelli C, Dolci G, Santoro A, Beghetto B, Menozzi M, Mussini C, Falutz J. Aging with HIV vs. HIV seroconversion at older age: a diverse population with distinct comorbidity profiles. PLoS One. 2015;10:e0118531.

6. Nguyen N, Holodniy M. HIV infection in the elderly. Clin Interv Aging. 2008; 3:453-72.

7. Friis-Moller $\mathrm{N}$, Weber $\mathrm{R}$, Reiss $\mathrm{P}$, Thiebaut $\mathrm{R}$, Kirk O, d'Arminio Monforte A, Pradier C, Morfeldt L, Mateu S, Law M, et al. Cardiovascular disease risk factors in HIV patients - association with antiretroviral therapy. Results from the DAD study. AIDS. 2003;17:1179-93.

8. Biggar RJ, Kirby KA, Atkinson J, McNeel TS, Engels E. Cancer risk in elderly persons with HIV/AIDS. J Acquir Immune Defic Syndr. 2004;36:861-8.

9. Anastos K, Lu D, Shi O, Mulligan K, Tien PC, Freeman R, Cohen MH, Justman J, Hessol NA. The association of bone mineral density with HIV infection and antiretroviral treatment in women. Antivir Ther. 2007;12:1049-58.

10. Buchacz K, Baker RK, Palella FJ Jr, Shaw L, Patel P, Lichtenstein KA, Chmiel $J S$, Vellozzi C, Debes R, Henry K, et al. Disparities in prevalence of key chronic diseases by gender and race/ethnicity among antiretroviral-treated HIV-infected adults in the US. Antivir Ther. 2013;18:65-75.

11. Alcaide ML, Parmigiani A, Pallikkuth S, Roach M, Freguja R, Della Negra M, Bolivar H, Fischl MA, Pahwa S. Immune activation in HIV-infected aging women on antiretrovirals_-implications for age-associated comorbidities: a cross-sectional pilot study. PLoS One. 2013;8:e63804

12. Gimeno-Gracia M, Crusells-Canales MJ, Javier Armesto-Gomez F, Rabanaque-Hernandez MJ. Prevalence of concomitant medications in older HIV+ patients and comparison with general population. HIV Clin Trials. 2015:16:117-24.

13. Burgess MJ, Zeuli JD, Kasten MJ. Management of HIV/AIDS in older patientsdrug/drug interactions and adherence to antiretroviral therapy. HIV AIDS (Auckl). 2015;7:251-64
14. Thurman AR, Anderson S, Doncel GF. Effects of hormonal contraception on anti-retroviral drug metabolism, pharmacokinetics and Pharmacodynamics. Am J Reprod Immunol (New York, NY : 1989). 2014;71:523-30.

15. Pyra M, Heffron R, Mugo NR, Nanda K, Thomas KK, Celum C, Kourtis AP, Were $E$, Rees $H$, Bukusi $E$, et al. Effectiveness of hormonal contraception in HIV-infected women using antiretroviral therapy: a prospective study. AIDS (London, England). 2015;29:2353-9.

16. Clark RA, Cohn SE, Jarek C, Craven KS, Lyons C, Jacobson M, Kamemoto L. Perimenopausal symptomatology among HIV-infected women at least 40 years of age. J Acquir Immune Defic Syndr. 2000;23:99-100.

17. Ferreira CE, Pinto-Neto AM, Conde DM, Costa-Paiva L, Morais SS, Magalhaes J. Menopause symptoms in women infected with HIV: prevalence and associated factors. Gynecol Endocrinol. 2007:23:198-205.

18. Kanapathipillai R, Hickey M, Giles M. Human immunodeficiency virus and menopause. Menopause. 2013:20:983-90.

19. Imai K, Sutton MY, Mdodo R, Del Rio C. HIV and menopause: a systematic review of the effects of HIV infection on age at menopause and the effects of menopause on response to antiretroviral therapy. Obstet Gynecol Int. 2013:2013:340309.

20. Grov C, Golub SA, Parsons JT, Brennan M, Karpiak SE. Loneliness and HIV-related stigma explain depression among older HIV-positive adults. AIDS Care. 2010;22: 630-9.

21. Heckman TG, Heckman BD, Kochman A, Sikkema KJ, Suhr J, Goodkin K. Psychological symptoms among persons 50 years of age and older living with HIV disease. Aging Ment Health. 2002;6:121-8.

22. Durvasula R. HIV/AIDS in older women: unique challenges, unmet needs. Behav Med. 2014:40:85-98.

23. Gurung RA, Taylor SE, Kemeny M, Myers H. "HIV is not my biggest problem": the impact of HIV and chronic burden on depression in women at risk for AIDS. J Soc Clin Psychol. 2004:23:490.

24. White Hughto JM, Reisner SL, Pachankis JE. Transgender stigma and health: a critical review of stigma determinants, mechanisms, and interventions. Soc Sci Med. 2015;147:222-31.

25. Wierckx K, Elaut E, Declercq E, Heylens G, De Cuypere G, Taes Y, Kaufman JM, T'Sjoen G. Prevalence of cardiovascular disease and cancer during cross-sex hormone therapy in a large cohort of trans persons: a case-control study. Eur J Endocrinol. 2013;169:471-8.

26. Gooren LJ, Wierckx K, Giltay EJ. Cardiovascular disease in transsexual persons treated with cross-sex hormones: reversal of the traditional sex difference in cardiovascular disease pattern. Eur J Endocrinol. 2014;170:809-19.

27. Gooren L, Lips P. Conjectures concerning cross-sex hormone treatment of aging transsexual persons. J Sex Med. 2014;11:2012-9.

28. Ferron P, Young S, Boulanger C, Rodriguez A, Moreno J. Integrated care of an aging HIV-infected male-to-female transgender patient. J Assoc Nurses AIDS Care. 2010;21:278-82

29. Sevelius JM, Carrico A, Johnson MO. Antiretroviral therapy adherence among transgender women living with HIV. J Assoc Nurses AIDS Care. 2010;21:256-64

30. Sangarlangkarn A, Appelbaum JS. Caring for older adults with the human immunodeficiency virus. J Am Geriatr Soc. 2016:64:2322-9.

31. Singh HK, Del Carmen T, Freeman R, Glesby MJ, Siegler EL. From one syndrome to many: incorporating geriatric consultation into HIV care. Clin Infect Dis. 2017;65:501-6

32. Adam GP, Di M, Cu-Uvin S, Halladay C, Smith BT, Trikalinos TA. AHRQ comparative effectiveness technical briefs. In: Strategies for improving the lives of women aged 40 and above living with HIV/AIDS. Rockville (MD): Agency for Healthcare Research and Quality (US); 2016.

33. Wallace BC, Small K, Brodley CE, Lau J, Trikalinos TA. Deploying an interactive machine learning system in an evidence-based practice center: abstrackr. Proc of the ACM International Health Informatics Symposium (IHI). 2012:819-24.

34. Dutcher MV, Phicil SN, Goldenkranz SB, Rajabiun S, Franks J, Loscher BS, Mabachi NM. "Positive examples": a bottom-up approach to identifying best practices in HIV care and treatment based on the experiences of peer educators. AIDS Patient Care STDs. 2011:25:403-11.

35. Cocohoba J, Comfort M, Kianfar $\mathrm{H}$, Johnson MO. A qualitative study examining HIV antiretroviral adherence counseling and support in community pharmacies. J Manag Care Pharm. 2013;19:454-60.

36. Sullivan KA, Schultz K, Ramaiya M, Berger M, Parnell H, Quinlivan EB. Experiences of women of color with a nurse patient navigation program for linkage and engagement in HIV care. AIDS Patient Care STDs. 2015;29(Suppl 1):S49-54 
37. Weiss SM, Tobin JN, Lopez M, Simons H, Cook R, Jones DL. Translating an evidence-based behavioral intervention for women living with HIV into clinical practice: the SMART/EST Women's program. Int J Behav Med. 2015;22:415-24.

38. Kupprat SA, Dayton A, Guschlbauer A, Halkitis PN. Case manager-reported utilization of support group, substance use and mental health services among HIV-positive women in new York City. AIDS Care. 2009;21:874-80.

39. Proeschold-Bell RJ, Reif S, Taylor B, Patkar A, Mannelli P, Yao J, Quinlivan EB. Substance use outcomes of an integrated HIV-substance use treatment model implemented by social workers and HIV medical providers. Health Soc Work. 2016:41:e1-e10.

40. Fletcher FE, Buchberg M, Schover LR, Basen-Engquist K, Kempf MC, Arduino $\mathrm{RC}$, Vidrine DJ. Perceptions of barriers and facilitators to cervical cancer screening among low-income, HIV-infected women from an integrated HIV clinic. AIDS Care. 2014;26:1229-35

41. Tello MA, Jenckes M, Gaver J, Anderson JR, Moore RD, Chander G. Barriers to recommended gynecologic care in an urban United States HIV clinic. J Women's Health (Larchmt). 2010;19:1511-8.

42. Blackstock OJ, Haughton LJ, Garner RY, Horvath KJ, Norwood C, Cunningham CO. General and health-related internet use among an urban, community-based sample of HIV-positive women: implications for intervention development. AIDS Care. 2015;27:536-44.

43. Blackstock OJ, Shah PA, Haughton $\sqcup$, Horvath KJ, Cunningham CO. HIV-infected women's perspectives on the use of the internet for social support: a potential role for online group-based interventions. J Assoc Nurses AIDS Care. 2015;26:411-9.

44. Cook JA, Burke-Miller JK, Grey DD, Cocohoba J, Liu C, Schwartz RM, Golub ET, Anastos K, Steigman PJ, Cohen MH. Do HIV-positive women receive depression treatment that meets best practice guidelines? AIDS Behav. 2014;18:1094-102.

45. Galarraga O, Salkever DS, Cook JA, Gange SJ. An instrumental variables evaluation of the effect of antidepressant use on employment among HIVinfected women using antiretroviral therapy in the United States: 19962004. Health Econ. 2010;19:173-88

46. Feaster DJ, Mitrani VB, Burns MJ, McCabe BE, Brincks AM, Rodriguez AE, Asthana D, Robbins MS. A randomized controlled trial of structural ecosystems therapy for HIV medication adherence and substance abuse relapse prevention. Drug Alcohol Depend. 2010;111:227-34.

47. Mitrani VB, McCabe BE, Burns MJ, Feaster DJ. Family mechanisms of structural ecosystems therapy for HIV-seropositive women in drug recovery. Health Psychol. 2012;31:591-600.

48. Neblett RC, Hutton HE, Lau B, McCaul ME, Moore RD, Chander G. Alcohol consumption among HIV-infected women: impact on time to antiretrovira therapy and survival. J Women's Health (Larchmt). 2011;20:279-86.

49. Chander G, Hutton HE, Lau B, Xu X, McCaul ME. Brief intervention decreases drinking frequency in HIV-infected, heavy drinking women: results of a randomized controlled trial. J Acquir Immune Defic Syndr. 2015;70:137-45.

50. Triant VA, Lee H, Hadigan C, Grinspoon SK. Increased acute myocardial infarction rates and cardiovascular risk factors among patients with human immunodeficiency virus disease. J Clin Endocrinol Metab. 2007;92:2506-12.

51. Lucas GM, Griswold M, Gebo KA, Keruly J, Chaisson RE, Moore RD. Illicit drug use and HIV-1 disease progression: a longitudinal study in the era of highly active antiretroviral therapy. Am J Epidemiol. 2006;163:412-20.

52. Pivnick A, Jacobson A, Blank AE, Villegas M. Accessing primary care: HIV+ Caribbean immigrants in the Bronx. J Immigr Minor Health. 2010;12:496-505.

53. Blackstock OJ, Blank AE, Fletcher JJ, Verdecias N, Cunningham CO. Considering care-seeking behaviors reveals important differences among HIV-positive women not engaged in care: implications for intervention. AIDS Patient Care STDs. 2015;29(Suppl 1):S20-6.

54. Sevelius JM, Patouhas E, Keatley JG, Johnson MO. Barriers and facilitators to engagement and retention in care among transgender women living with human immunodeficiency virus. Ann Behav Med. 2014;47:5-16.

55. Williams CT, Kim S, Meyer J, Spaulding A, Teixeira P, Avery A, Moore K, Altice F, Murphy-Swallow D, Simon D, et al. Gender differences in baseline health, needs at release, and predictors of care engagement among HIV-positive clients leaving jail. AIDS Behav. 2013;17(Suppl 2):S195-202.

56. Tariq S, Delpech $V$, Anderson J. The impact of the menopause transition on the health and wellbeing of women living with HIV: a narrative review. Maturitas. 2016;88:76-83

57. Calvet GA, Grinsztejn BG, Quintana Mde S, Derrico M, Jalil EM, Cytryn A, de Andrade AC, Moreira RI, Alves MR, Veloso Dos Santos VG, Friedman RK. Predictors of early menopause in HIV-infected women: a prospective cohort study. Am J Obstet Gynecol. 2015;212:765. e761-765.e713
58. Kojic EM, Wang CC, Cu-Uvin S. HIV and menopause: a review. J Women's Health (Larchmt). 2007:16:1402-11.

59. Schoenbaum EE, Hartel D, Lo Y, Howard AA, Floris-Moore M, Arnsten JH, Santoro N. HIV infection, drug use, and onset of natural menopause. Clin Infect Dis. 2005;41:1517-24.

60. Halladay CW, Trikalinos TA, Schmid IT, Schmid CH, Dahabreh IJ. Using data sources beyond PubMed has a modest impact on the results of systematic reviews of therapeutic interventions. J Clin Epidemiol. 2015;68:1076-84.

61. Moher D, Liberati A, Tetzlaff J, Altman DG. Preferred reporting items for systematic reviews and meta-analyses: the PRISMA statement. Ann Intern Med. 2009:151:264-9. w264

62. Abel E. Women with HIV and stigma. Fam Community Health. 2007;30:5104-6.

63. Echenique M, Illa L, Saint-Jean G, Avellaneda VB, Sanchez-Martinez M, Eisdorfer C. Impact of a secondary prevention intervention among HIVpositive older women. AIDS Care. 2013:25:443-6.

64. Feaster DJ, Brincks AM, Mitrani VB, Prado G, Schwartz SJ, Szapocznik J. The efficacy of structural ecosystems therapy for HIV medication adherence with African American women. J Fam Psychol. 2010;24:51-9.

65. Teti M, Bowleg L, Cole R, Lloyd L, Rubinstein S, Spencer S, Aaron E, Ricksecker A, Berhane Z, Gold M. A mixed methods evaluation of the effect of the protect and respect intervention on the condom use and disclosure practices of women living with HIV/AIDS. AIDS Behav. 2010;14:567-79.

66. El-Bassel N, Jemmott JB III, Landis JR, Pequegnat W, Wingood GM, Wyatt GE, Bellamy SL. Intervention to influence behaviors linked to risk of chronic diseases: a multisite randomized controlled trial with African-American HIVserodiscordant heterosexual couples. Arch Intern Med. 2011:171:728-36.

67. DeMarco RF, Chan K. The Sistah Powah structured writing intervention: a feasibility study for aging, low-income, HIV-positive black women. Am J Health Promot. 2013;28:108-18.

68. Manuel JK, Lum PJ, Hengl NS, Sorensen JL. Smoking cessation interventions with female smokers living with HIV/AIDS: a randomized pilot study of motivational interviewing. AIDS Care. 2013;25:820-7.

69. Burke-Miller JK, Cook JA, Cohen MH, Hessol NA, Wilson TE, Richardson JL, Williams P, Gange SJ. Longitudinal relationships between use of highly active antiretroviral therapy and satisfaction with care among women living with HIV/AIDS. Am J Public Health. 2006;96:1044-51.

70. Toth M, Messer LC, Quinlivan EB. Barriers to HIV care for women of color living in the southeastern US are associated with physical symptoms, social environment, and self-determination. AIDS Patient Care STDs. 2013;27:613-20.

71. Stevens PE, Keigher SM. Systemic barriers to health care access for U.S. women with HIV: the role of cost and insurance. Int J Health Serv. 2009:39:225-43.

72. Quinlivan EB, Messer LC, Adimora AA, Roytburd K, Bowditch N, Parnell H, Seay J, Bell L, Pierce JK. Experiences with HIV testing, entry, and engagement in care by HIV-infected women of color, and the need for autonomy, competency, and relatedness. AIDS Patient Care STDs. 2013;27:408-15.

73. Vyavaharkar M, Moneyham L, Tavakoli A, Phillips KD, Murdaugh C, Jackson K Meding G. Social support, coping, and medication adherence among HIVpositive women with depression living in rural areas of the southeastern United States. AIDS Patient Care STDs. 2007;21:667-80.

74. McDoom MM, Bokhour B, Sullivan M, Drainoni ML. How older black women perceive the effects of stigma and social support on engagement in HIV care. AIDS Patient Care STDs. 2015;29:95-101.

75. Kempf MC, McLeod J, Boehme AK, Walcott MW, Wright L, Seal P, Norton WE, Schumacher JE, Mugavero M, Moneyham L. A qualitative study of the barriers and facilitators to retention-in-care among HIV-positive women in the rural southeastern United States: implications for targeted interventions. AIDS Patient Care STDs. 2010;24:515-20.

76. Sarnquist CC, Soni S, Hwang H, Topol BB, Mutima S, Maldonado YA. Rural HIV-infected women's access to medical care: ongoing needs in California. AIDS Care. 2011;23:792-6. 